\title{
A 90 DAY SUPPLEMENTATION OF POLYUNSATURATED FATTY ACIDS (PUFA) HAS BENEFITS ON HEALTH MEASURES AND EXERCISE PERFORMANCE
}

\author{
Márta Ránky ${ }^{1}$, Ferenc Köteles ${ }^{1}$, Csaba Nyakas ${ }^{2}$, György Bárdos ${ }^{1}$, Attila Szabo ${ }^{1,3}$ \\ Institute of Health Promotion and Sport Sciences ${ }^{1}$, Eötvös Loránd University, Budapest, Hungary \\ Research Institute of Sport Sciences ${ }^{2}$, Hungarian University of Physical Education, Budapest, Hungary \\ Institute of Psychology³, Eötvös Loránd University, Budapest, Hungary
}

\begin{abstract}
Background. Fish oil contains essential fatty acids that are linked to better cardiovascular health and even the prevention of sudden cardiac death in athletes. The purpose of this work was to examine the effects of 90 days of fish oil supplementation in elite-, leisure-, and non-athletes on body fat percent, body mass index (BMI), blood cholesterol and triglycerides, heart rate and blood pressure, and on exercise performance.

Method. Three groups of participants were tested with 12 equally distributed men and women in each: eliteathletes, leisure-athletes, and non-athletes. Participants received body weight-adjusted commercially available fish oil over 90 days. These nutritional supplements were taken in the morning, immediately following breakfast.

Results. The findings revealed that compared to the baseline, body fat percent decreased in all the three groups ( $p=$ $.034)$, however, blood cholesterol and the cholesterol/high density lipoprotein (HDL) ratio increased $(p<.05)$, with the elite-athletes showing the largest increase. Exercise performance, in terms of the time of running to voluntary exhaustion, increased $(p=.05)$, but the largest benefits were observed in non-athletes $(22 \%)$ in contrast to leisureathletes $(4 \%)$ and elite-athletes (1\%), which could be linked to a ceiling effect. No statistically significant changes were observed in any other anthropometric, physiological, or biochemical measures.

Conclusion. These findings suggest that 90 days of fish oil supplementation may benefit body composition and increase exercise performance, especially in non-athletes, and increases cholesterol, as well as cholesterol/HDL ratio levels, primarily in elite-athletes. Based on these results, it appears that fish oil supplementation yields greater benefits in non-athletes than in athletes.
\end{abstract}

Keywords: anthropometric measures, biochemical measures, body composition, in-situ, real life setting.

\section{INTRODUCTION}

$\mathrm{L}$ ong-chain omega (n)-3 polyunsaturated fatty acids (LC-PUFAs; e.g. eicosapentaeoic acid-EPA, or docosahexaenoic acid-DHA) have well-documented anti-inflammatory and antioxidant effects (Deckelbaum \& Torrejon, 2012). PUFAs were found to be beneficial in the prevention and treatment of various cardiovascular diseases due to their triglyceride-lowering, anti-thrombotic, anti-inflammatory, and anti-hypertensive properties (Breslow, 2006; Deckelbaum \& Torrejon, 2012; Kotwal, Jun, Sullivan, Perkovic, \& Neal, 2012;
Marik \& Varon, 2009). In addition to cardiovascular effects, PUFAs promote early eye and brain development (Gódor-Kacsándi, Felszeghy, Ranky, Luiten, \& Nyakas, 2013; Walker, Jebb, \& Calder, 2013), regulate the immune function (Gorjão et al., 2006), and can improve inflammatory conditions such as arthritis (Calder, 2013; Serhan, Chiang, \& Van Dyke, 2008). Based on these considerations, recent dietary guidelines recommend regular consumption of seafood to increase intake of PUFAs (Papanikolaou, Brooks, Reider, \& Fulgoni, 2014). 
Beyondhealthpromotionanddiseaseprevention, PUFAs also reduce exercise-related oxidative stress, immune and inflammatory responses to exercise, and soreness (Andrade, Ribeiro, Bozza, Costa Rosa, \& do Carmo, 2007; Gray, Chappell, Jenkinson, Thies, \& Gray, 2014; Jouris, McDaniel, \& Weiss, 2011; Lembke, Capodice, Hebert, \& Swenson, 2014). These positive effects can lead to the improvement of exercise performance. For example, in a recent study examining 30 male athletes, a 21-day administration of PUFAs $(5 \mathrm{ml}$ sea oil per day, containing, $375 \mathrm{mg}$ EPA, $230 \mathrm{mg}$ DPA, and $10 \mathrm{mg}$ DHA) significantly improved peripheral neuromuscular function and aspects of fatigue compared to olive oil placebo. On the other hand, no beneficial effect on the central neuromuscular function was reported (Lewis, Radonic, Wolever, \& Wells, 2015). In another placebo-controlled study, no improvement in the maximal aerobic power, anaerobic threshold and running performance was found in 28 welltrained male soccer players following a 10 -week supplementation of PUFAs $(1600 \mathrm{mg} /$ day EPA, $1004 \mathrm{mg} /$ day DHA) which led to the conclusion that the maximal aerobic performance of endurance athletes cannot be improved by PUFAs (Raastad, Høstmark, \& Strømme, 1997). According to a recent review, available empirical data regarding the positive impact of PUFAs on exercise performance are inconclusive, and, therefore further studies are needed to assess the effectiveness of PUFAs supplementation on delayed onset muscle soreness, and subsequent exercise performance in eliteathletes and military personnel (Shei, Lindley, \& Mickleborough, 2014).

The effectiveness of PUFAs may also depend on the intensity of exercise and the training status of the participants. In a recent study, untrained males receiving a green-lipped mussel oil PUFA blend for 26 days showed a significant decrease of muscle damage and strength loss compared to the a placebo control group after a muscle damaging exercise (Mickleborough, Sinex, Platt, Chapman, \& Hirt, 2015). In the current research, the effects of 90-day PUFA supplementation were assessed on measures of exercise performance, blood lipid profiles, and cardiovascular indices in three groups of participants with different training status (i.e. elite endurance athletes, leisure runners, and individuals with a sedentary lifestyle). Complementing past research, we report here the effects of PUFAs over a longer period (90 days) of administration, on anthropometric, physiological, biochemical, as well as exercise performance variables, and in function of training status. It was conjectured that this multi-level repeated measures factorial design will yield a clearer picture about the effects of PUFAs on health- and exercise-behaviour.

\section{METHODS}

Participants. Elite-athletes were competitive triathletes and elite endurance runners. They were recruited with the assistance of the national athletics and triathlon associations, who sent a call for participation e-mail to their athletes and also presented them with recruitment flyers in the upcoming competitions. Leisure-athletes were recruited before street running races in a large metropolitan area, while the control, non-athlete, participants were recruited from social media targeting groups interested in health and fitness. Thirty-six participants completed the study. Ethical permission for the study was obtained from the Ethics Research Board of the National Healthcare Scientific Committee. Elite-athletes trained between 24-36 hours per week. Their mean age was $22.35 \pm 2.61$ (men) and $23.63 \pm 2.84$ (women) years. The leisure-athletes (runners) trained an average of 9-12 hours per week and their mean age was $38.09 \pm 8.37$ (men) and $40.76 \pm 7.46$ (women) years. The non-athlete control participants did not report any scheduled exercise ( 0 hours per week). Their mean age was $31.97 \pm 7.48$ (men) and $27.55 \pm$ 5.05 (women) years.

Materials. A known commercial brand of fish oil capsule was provided to all the participants. Based on the manufacturer's information, six (6) capsules contained $138.12 \mathrm{~kJ}(32.88 \mathrm{kcal})$ of energy, $0.786 \mathrm{~g}$ protein, $0.355 \mathrm{mg}$ carbohydrates, $2.94 \mathrm{~g}$ fat, $741 \mathrm{mg}$ saturated fatty acids, $703 \mathrm{mg}$ monounsaturated fatty acids, $1293 \mathrm{mg}$ polyunsaturated fatty acids of which $529 \mathrm{mg}$ EPA, $353 \mathrm{mg}$ DHA, and $6 \mathrm{mg}$ vitamin E. Exercise was performed on a Spiroergometer (Schiller CS-200, ITAM) treadmill with heart rate and blood pressure reading functions (Schiller BP-200 Plus).

Procedure. Prior to the investigation, participants were informed verbally and in writing about the purpose of the research. They were interviewed about their health status and informed about any possible complications that may arise during the course of the study. If the participant agreed to take part in the study, she/he signed a 
written informed consent form. By signing the form, the participants declared that they will not make changes in their usual diet and that they will not consume any other unsaturated fatty acids during the course of the study, apart from the one supplied to them by the researchers. All tests (described below) were performed twice: on day zero (baseline) and on day 91.

Upon coming to the laboratory, participants were asked to relax in preparation for blood tests in which $15 \mathrm{ml}$ of whole blood was collected by a qualified medical personnel. The cellular elements of the blood were destroyed after diagnosis as the norms of the relevant legislation require. Blood samples were stored in a refrigerator at $4^{\circ} \mathrm{C}$ until they were transported to the laboratory in a cool box where the blood samples were analyzed for lipid profiles.

Anthropometric measurements were performed according to the International Biological Program recommendations (Weiner \& Lourie, 1981). In this analysis, the two-component body composition estimation is based on Pariscova's recommendation and requires body weight and 5-skinfold (plica of biceps, triceps, scapula, hip, medial crural) measurements (Parízková \& Bůzková, 1971), which were recorded on the basis of the International Society for the Advancement of Kinanthropometry (ISAK) method (Stewart \& Marfell-Jones, 2011). Anthropometric variables included height, weight, abdominal circumference, skinfold measurements to determine body fat, body mass, relative bonemuscle ratio and fat mass determination based on the Drinkwatter and Ross procedure (Drinkwater \& Ross, 1980).

Participants took fish oil capsules every morning after their breakfast for 90 days. Based on their body weight assessed on Day 0 (baseline), those under $55 \mathrm{~kg}$ received 4, those between 55 and $70 \mathrm{~kg}$ received 5 and those above $70 \mathrm{~kg}$ received 6 capsules for every day in the study. On days 0 and 91 we have performed anthropometric tests, collected venous blood for lipid analysis, measured resting heart rate and blood pressure, and tested participants on a two part ergometer test using a treadmill. After obtaining all measures at rest, the participants completed the "Vita Maxima" ergospirometric test (Fostikov, 1971), consisting of running at $8 \mathrm{~km} /$ hour steady speed starting with a $4.0 \%$ elevation (incline) that was increased by $1.5 \%$ every minute until exhaustion. After a half an hour of relaxation, the participants run again at the elevation corresponding to their $85 \%$ of maximal oxygen uptake $\left(\mathrm{VO}_{2} \max \right)$ until voluntary exhaustion.

Data were analysed with the SPSS 20.0 statistical software package. Since none of the variables violated the assumption of normal distribution as based on preliminary Kolmogorov-Smirnov statistical tests - the data were examined with parametric statistics. Mixed (between (groups) and within (change with time) repeated measures analyses of variances were used, which were followed up with Bonferroni-corrected post hoc tests. For tests involving repeated measures, the Greenhouse-Geisser correction of the degrees of freedom was adopted.

\section{RESULTS}

The descriptive statistics of the dependent measures are presented in Table 1. A repeated measures analysis of variance (RMANOVA) of body fat percent yielded a time main effect $(F(1$, $33)=4.918, p=.034)$, as well as a group main effect $(F(2,33)=4.624, p=.017)$, but no group by time interaction $(F(2,33)=1.081, p=.351)$. Posthoc tests showed that the overall body fat percent has decreased $4.8 \%\left(t_{0}=20.15 \pm 6.15, t_{1}=19.18 \pm\right.$ $5.39, p=.034)$. The between-group main effect was due to the fact that elite-athletes already differed on Day 0 from non-athletes $(p=.023)$ and also but only marginally - from the leisure-athletes ( $p=.071)$, while the latter two did not differ from each other (Table).

The analysis of the body mass index (BMI) only yielded a statistically significant group main effect $(F(2,33)=3.452, p=.044)$, which substantiated that the BMI differed between eliteathletes and non-athletes $(p=.044)$ already on Day 0 . Blood cholesterol levels showed a statistically significant time main effect $(F(1,33)=5.325$, $p=.027)$, but no group main effect and no group by time interaction. Post hoc tests revealed that overall blood cholesterol levels have increased $4.1 \%$ after 90 days of fish oil consumption $\left(t_{0}=4.95 \pm 0.82\right.$, $\left.\mathrm{t}_{1}=5.16 \pm 0.84, p=.027\right)$. The analysis of the ratio of total blood cholesterol to high-density lipoprotein (HDL) yielded a statistically significant time main effect $(\mathrm{F}(1,33)=16.914, \mathrm{p}<0.001)$, a group main effect $(F(1,33)=3.44, p=0.044)$, but no group by time interaction. Post hoc tests showed that the 
Table. Changes in the dependent measures over 90 days in three groups

\begin{tabular}{|c|c|c|c|c|}
\hline Time & Dependent Measure & Elite-athletes & Leisure- athletes & Non-athletes \\
\hline Pre & Body fat (t0) (\%) & $16.06 \pm 5.86$ & $21.70 \pm 4.68$ & $22.69 \pm 6.03$ \\
\hline Post & Body fat (t1) (\%) & $16.00 \pm 5.23$ & $20.31 \pm 5.47$ & $21.24 \pm 4.27$ \\
\hline Pre & BMI (t0) $\left(k g / m^{2}\right)$ & $20.49 \pm 1.51$ & $23.05 \pm 3.35$ & $24.33 \pm 5.27$ \\
\hline Post & $\mathrm{BMI}(\mathrm{t} 1)\left(\mathrm{kg} / \mathrm{m}^{2}\right)$ & $20.60 \pm 1.33$ & $23.17 \pm 3.25$ & $24.43 \pm 5.17$ \\
\hline Pre & Blood cholesterol (t0) $(\mathrm{mmol} / \mathrm{l})$ & $4.54 \pm 0.74$ & $5.32 \pm 0.96$ & $5.00 \pm 0.60$ \\
\hline Post & Blood cholesterol (t1) $(\mathrm{mmol} / \mathrm{l})$ & $4.92 \pm 0.87$ & $5.47 \pm 0.87$ & $5.08 \pm 0.76$ \\
\hline Pre & Total cholesterol/HDL (t0) $(\mathrm{mmol} / \mathrm{l})$ & $2.39 \pm 0.41$ & $2.83 \pm 0.59$ & $3.12 \pm 0.77$ \\
\hline Post & Total cholesterol/HDL (t1) $(\mathrm{mmol} / \mathrm{l})$ & $2.86 \pm 0.59$ & $3.31 \pm 0.73$ & $3.43 \pm 0.94$ \\
\hline Pre & Triglyceride $(\mathrm{t} 0)(\mathrm{mmol} / \mathrm{l})$ & $0.99 \pm 0.35$ & $0.97 \pm 0.37$ & $1.20 \pm 0.77$ \\
\hline Post & Triglyceride (t1) ( $\mathrm{mmol} / \mathrm{l})$ & $0.86 \pm 0.42$ & $0.93 \pm 0.34$ & $1.26 \pm 0.70$ \\
\hline Pre & Resting heart rate $(\mathrm{t} 0)(\mathrm{bpm})$ & $57.08 \pm 13.00$ & $66.00 \pm 9.22$ & $71.92 \pm 13.65$ \\
\hline Post & Resting heart rate $(\mathrm{t} 1)(\mathrm{bpm})$ & $57.08 \pm 10.20$ & $63.50 \pm 12.48$ & $66.58 \pm 11.99$ \\
\hline Pre & Systolic blood pressure (t0) ( $\mathrm{mm} \mathrm{Hg}$ ) & $127.67 \pm 12.82$ & $126.92 \pm 16.16$ & $125.33 \pm 11.11$ \\
\hline Post & Systolic blood pressure (t1) $(\mathrm{mm} \mathrm{Hg})$ & $125.75 \pm 10.51$ & $125.92 \pm 11.76$ & $120.42 \pm 8.03$ \\
\hline Pre & Diastolic blood pressure (t0) $(\mathrm{Hgmm})$ & $65.83 \pm 9.25$ & $71.17 \pm 9.71$ & $69.08 \pm 5.81$ \\
\hline Post & Diastolic blood pressure (t1) $(H g m m)$ & $63.92 \pm 7.57$ & $70.92 \pm 6.69$ & $68.33 \pm 8.44$ \\
\hline Pre & Time to exhaustion $(\mathrm{t} 0)(s)$ & $770.00 \pm 159.60$ & $595.83 \pm 151.75$ & $439.17 \pm 94.34$ \\
\hline Post & Time to exhaustion $(\mathrm{t} 1)(s)$ & $777.50 \pm 174.15$ & $622.50 \pm 150.10$ & $561.67 \pm 179.54$ \\
\hline Pre & Exercise performance $(\mathrm{t} 0)(W)$ & $370.75 \pm 178.26$ & $287.25 \pm 66.22$ & $256.67 \pm 69.56$ \\
\hline Post & Exercise performance $(\mathrm{t} 1)(W)$ & $312.83 \pm 69.65$ & $285.75 \pm 62.25$ & $267.25 \pm 70.44$ \\
\hline
\end{tabular}

Notes. Day $0\left(t_{0}\right)=$ baseline (Pre); time $2\left(t_{2}\right)=$ after 90 days (Post); data are presented as means \pm standard deviations.

total cholesterol to HDL ratio has increased by $13 \%$ over time $\left(t_{0}=2.78 \pm 0.67, t_{1}=3.20 \pm 0.78\right)$ and that elite-athletes differed from the non-athletes only ( $p=.045)$, while the latter did not differ from the leisure-athletes. No statistically significant effects have emerged in triglycerides, resting heart rate, diastolic- and systolic blood pressure.

The analysis of the duration of exercise to exhaustion yielded a statistically significant time main effect $(F(1,33)=8.972, p=.005)$, a group main effect $(F(2,33)=10.815, p<.001)$, and a group by time interaction $(F(2,33)=4.163, p=$ .024). The time main effect reflected an increased endurance performance across the 90 days of dietary fish oil supplementation $\left(t_{0}=601.67 \pm\right.$ $\left.23.054, t_{1}=653.89 \pm 28.069, p=.005\right)$, and the performance of the elite-athletes was significantly better than that of the participants in the other two groups, which did not differ from each other. The elite-athletes' performance did not change after the treatment, probably due to a ceiling effect since their performance was much better already initially than that of the two other groups. On the contrary, the other two groups had increased their performance, the leisure-athlete group with a statistically significant increase of $21.8 \%$ (see Figure and Table) from baseline to the second assessment $(t(11)=-2.73, p=.02)$. 
Figure. Diagram the group by time interaction obtained for the performance time to exhaustion in three groups

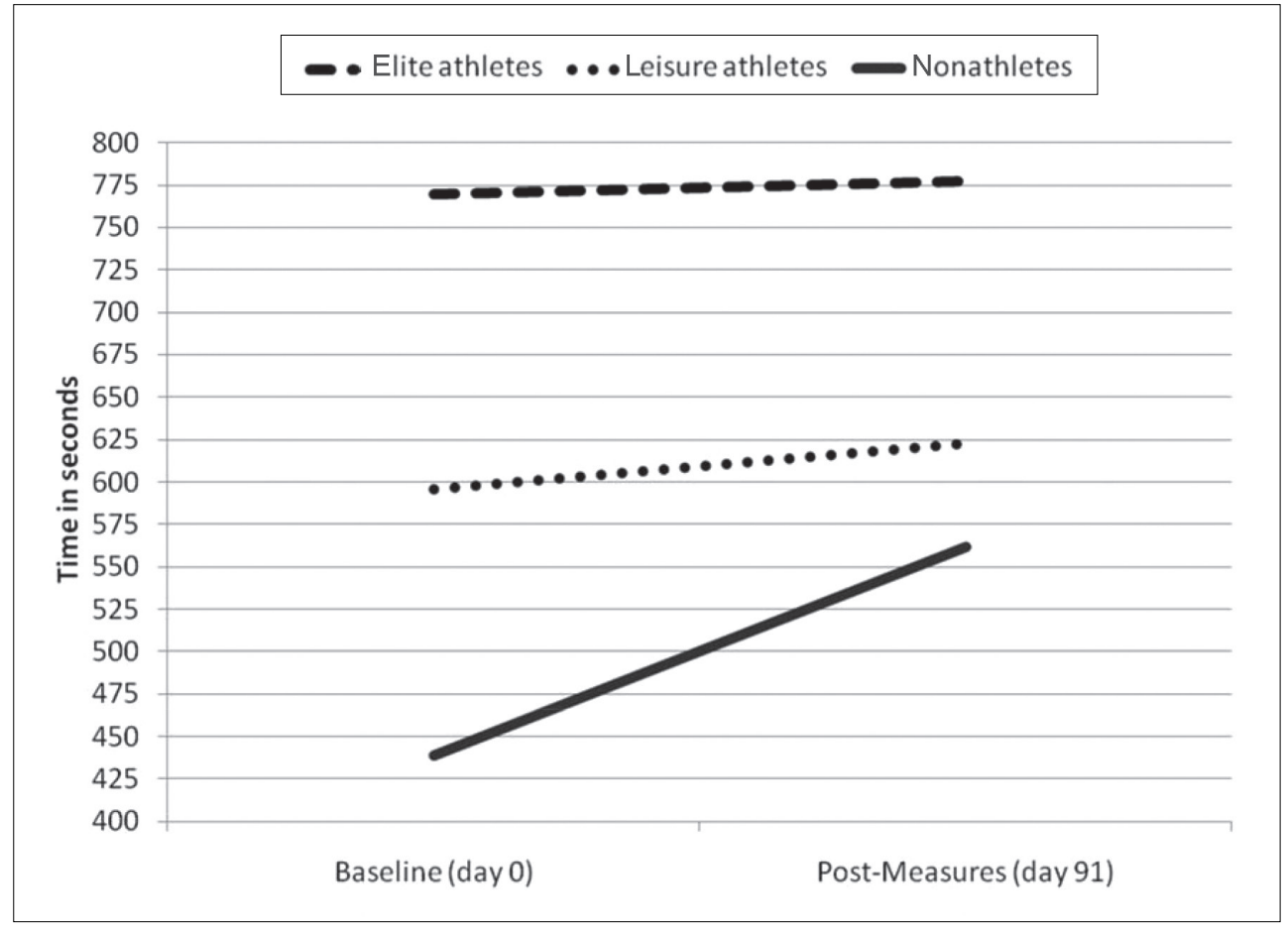

\section{DISCUSSION}

The current findings show that PUFA supplementation may reduce body fat percent. In spite of the lack of emergence of a group by time interaction, from Table 1 it emerges that leisureathletes and non-athletes profited the most since the overall $4.8 \%$ decrease over time was due to over $6 \%$ decrease in these two groups, while elite-athletes showed virtually no change in this measure. These findings agree with past research showing that PUFA supplementation reduces body fat (Couet, Delarue, Ritz, Antoine, \& Lamisse, 1997; Hill, Buckley, Murphy, \& Howe, 2007).

In spite of reports from the literature claiming that PUFA reduces triglyceride levels in the blood (Gidding et al., 2014; Oelrich, Dewell, \& Gardner, 2013; Shearer, Savinova, \& Harris, 2012), in the current work triglyceride profiles were unaffected by PUFA supplementation. The most likely explanation may be linked to the small dose (under $1 \mathrm{~g}$ /day EPA and DHA) of PUFA administered in the current work. Earlier, it was suggested that a moderate dose of $4 \mathrm{~g}$ /day is needed to lower triglyceride levels in the blood (Miller et al., 2011). According to the recommendations of the Federal Drug Administration, the intake of consumers should not exceed $3 \mathrm{~g}$ /day of EPA plus DHA with no more than $2 \mathrm{~g}$ /day from dietary supplementation (Bradberry \& Hilleman, 2013). Therefore, the dose of PUFA used in the current inquiry was probably too small to yield changes in plasma triglycerides.

Fish oil supplementation resulted in a slightly increased blood cholesterol level (4.1\%), as well as increased total cholesterol/HDL ratio (13\%), independent of the participants' training status.

We have no clear explanation for this novel observation. There are three possible mechanisms, however: 1) Total blood fat content has increased as a result of the PUFA consumption, which triggered an increased cholesterol release from the cell membranes; 2) The liver could not process the increased fat intake (which is unlikely given the low dose used in the current study); 3) Some components of the PUFA containing fish oil capsules may be metabolised in the same way as the cholesterol, which may slow down cholesterol metabolism.

A 90 day of fish oil supplementation did not have a statistically significant effect on resting heart rate in the current work. To some extent these findings appear to be in contrast to a large scale populationbased study that revealed a decrease in heart rate (Dallongeville et al., 2003). Indeed, it was shown that regular fish consumption may be associated with a heart rate reduction of approximately 3.2 beats per minute (bpm) (Mozaffarian, Prineas, Stein, \& Siscovick, 2006). These authors also found that an estimate of $1 \mathrm{~g}$ /day PUFA intake may be associated with a heart rate reduction of 2.3 
bpm. The current findings are still consistent with Mozaffarian et al.'s report in that resting heart rate decreased an average of $2.5 \mathrm{bpm}$ in leisure-athletes (runners) and by more than $5 \mathrm{bpm}$ in non-athletes, in spite of the fact that a statistically significant group by time interaction could not be disclosed* which was probably due to a high variance, as well as relatively low sample size, in the studied sample. The failure to see lower resting heart rate in eliteathletes (exhibiting nearly the same heart rate at pre- and post-assessment), may be ascribed to a floor effect.

The effect of PUFA supplementation in lowering blood pressure may be the most prominent in hypertensive patients; the reduction is usually relatively small and also dose dependent (Morris, Sacks, \& Rosner, 1993). Several studies did not yield an effect on healthy subjects (Morris, Sacks, \& Rosner, 1993), but at higher doses (i.e. > 3g/day) PUFAs were effective in reducing both systolic blood pressure (SBP) and diastolic blood pressure (DBP) (Appel, Miller, Seidler, \& Whelton, 1993; Cabo, Alonso, \& Mata, 2012). It was recommended that the hypotensive effects of lower doses of fish oil supplementation $(<0.5 \mathrm{~g} /$ day $)$ should be further evaluated (Geleijnse, Giltay, Grobbee, Donders, \& Kok, 2002). Using a lower dose in the current study, no hypotensive effects of the PUFAs were observed. These findings are in accord with the conclusion of a recent meticulous meta-analysis of clinical trials showing that administration of $\geq 2$ g/day PUFA may reduce both SBP and DBP, with the largest benefits seen among hypertensive patients who are not on medication. Further, a lower dose (between 1 and $2 \mathrm{~g} /$ day - that is higher than the dose used in the current work - may reduce SBP, but not DBP (P. Miller, Van Elswyk, \& Alexander, 2014).

In partial accord with a recent report (Lewis et al., 2015), fish oil supplementation resulted in increased exercise performance, however, the noticed increase was statistically significant only in the non-athletes, while no changes were seen in athletes. These findings are consistent with a recent review (Macaluso et al., 2013) showing that the majority of studies could not reveal a benefit of fish oil supplementation on exercise performance in athletes. Volpe also came to the same conclusion and recommended more systematic studies (Volpe, 2012). In the current work, two levels of athletic involvement were studied by testing a group of elite triathlon and endurance runner competitors and a group of regular, but leisure-athletes. None of them showed improvement in running to voluntary exhaustion after 90 days of fish oil consumption, thus adding further data to the bulk of the studies that failed to disclose a positive link between PUFAs and exercise performance. The increase in exercise performance in non-athletes could be the manifestation of a metabolic effect induced in some way, perhaps by active energy intake represented by long term fish oil consumption, or a placebo effect associated with the PUFA supplementation.

\section{CONCLUSIONS}

Regardless of athletic or exercise status, a relatively modest dose of fish oil supplementation lowers body fat and increases cholesterol, as well as cholesterol/HDL ratio; It also tends to reduce resting heart rate in leisure-athletes and nonathletes, but not in the elite-athletes. A low dose of PUFA supplement could be used to increase exercise performance, decrease resting heart rate, and alter body composition especially in nonathletes and leisure-athletes.

Acknowledgements. This research was supported by the National Scientific Research Fund (OTKA K 109549).

Conflict of interest. The authors have no conflict of interest, of any kind, to declare.

\section{REFERENCES}

Andrade, P. M. M., Ribeiro, B. G., Bozza, M. T., Costa Rosa, L. F. B., \& do Carmo, M. G. T. (2007). Effects of the fish-oil supplementation on the immune and inflammatory responses in elite swimmers. Prostaglandins Leukotrienes and Essential Fatty

\footnotetext{
* A group by time RMANOVA excluding the elite athletes, yielded a statistically significant time main effect, showing a decrease in heart rate in the leisure athletes and nonathletes only $(F(1,22)=4.7, p=.041)$.
}

Acids, 77(3-4), 139-145. https://doi.org/10.1016/j. plefa.2007.08.010

Appel, L. J., Miller, E. R., Seidler, A. J., \& Whelton, P. K. (1993). Does supplementation of diet with "fish oil" reduce blood pressure? A meta-analysis of controlled clinical trials. Archives of Internal Medicine, 153(12), 1429-1438.

Bradberry, J. C., \& Hilleman, D. E. (2013). Overview of Omega-3 Fatty Acid Therapies. Pharmacy and Therapeutics, 38(11), 681-691. 
Breslow, J. L. (2006). n-3 fatty acids and cardiovascular disease. The American Journal of Clinical Nutrition, 83(Suppl. 6), 1477S-1482S.

Cabo, J., Alonso, R., \& Mata, P. (2012). Omega-3 fatty acids and blood pressure. The British Journal of Nutrition, 107(Suppl. 2), S195-200. https://doi. org/10.1017/S0007114512001584

Calder, P. C. (2013). Omega-3 polyunsaturated fatty acids and inflammatory processes: Nutrition or pharmacology? British Journal of Clinical Pharmacology, 75(3), 645662. https://doi.org/10.1111/j.1365-2125.2012.04374.x

Couet, C., Delarue, J., Ritz, P., Antoine, J. M., \& Lamisse, F. (1997). Effect of dietary fish oil on body fat mass and basal fat oxidation in healthy adults. International Journal of Obesity, 21, 637-643.

Dallongeville, J., Yarnell, J., Ducimetière, P., Arveiler, D., Ferrières, J., Montaye, M., ... Amouyel, P. (2003). Fish consumption is associated with lower heart rates. Circulation, 108(7), 820-825. https://doi. org/10.1161/01.CIR.0000084542.64687.97

Deckelbaum, R. J., \& Torrejon, C. (2012). The omega-3 fatty acid nutritional landscape: Health benefits and sources. The Journal of Nutrition, 142(3), 587S-591S. https://doi.org/10.3945/jn.111.148080

Drinkwater, D. T., \& Ross, W. D. (1980). Anthropometric fractionation of body mass. In M. Ostyn, G. Beunen, \& J. Simons (Eds.), Kinanthropometry II (pp. 178-189). Baltimore: University Park Press.

Fostikov, B. (1971). The vita maxima spiroergometric test and its value in the evaluation of cardiorespiratory function. Plućne Bolesti I Tuberkuloza, 23(1), 72-79.

Geleijnse, J. M., Giltay, E. J., Grobbee, D. E., Donders, A. R. T., \& Kok, F. J. (2002). Blood pressure response to fish oil supplementation: Metaregression analysis of randomized trials. Journal of Hypertension, 20(8), 1493-1499.

Gidding, S. S., Prospero, C., Hossain, J., Zappalla, F., Balagopal, P. B., Falkner, B., \& Kwiterovich, P. (2014). A double-blind randomized trial of fish oil to lower triglycerides and improve cardiometabolic risk in adolescents. The Journal of Pediatrics, 165(3), 497503.e2. https://doi.org/10.1016/j.jpeds.2014.05.039

Gódor-Kacsándi, A., Felszeghy, K., Ranky, M., Luiten, P. G. M., \& Nyakas, C. (2013). Developmental docosahexaenoic and arachidonic acid supplementation improves adult learning and increases resistance against excitotoxicity in the brain. Acta Physiologica Hungarica, 100(2), 186-196. https://doi.org/10.1556/ APhysiol.100.2013.005

Gorjão, R., Verlengia, R., Lima, T. M. d., Soriano, F. G., Boaventura, M. F. C., Kanunfre, C. C., ... Curi, R. (2006). Effect of docosahexaenoic acid-rich fish oil supplementation on human leukocyte function. Clinical Nutrition, 25(6), 923-938. https://doi.org/10.1016/j. clnu.2006.03.004

Gray, P., Chappell, A., Jenkinson, A. M., Thies, F., \& Gray, S. R. (2014). Fish oil supplementation reduces markers of oxidative stress but not muscle soreness after eccentric exercise. International Journal of Sport
Nutrition and Exercise Metabolism, 24(2), 206-214. https://doi.org/10.1123/ijsnem.2013-0081

Hill, A. M., Buckley, J. D., Murphy, K. J., \& Howe, P. R. C. (2007). Combining fish-oil supplements with regular aerobic exercise improves body composition and cardiovascular disease risk factors. The American Journal of Clinical Nutrition, 85(5), 1267-1274.

Jouris, K. B., McDaniel, J. L., \& Weiss, E. P. (2011). The Effect of Omega-3 Fatty Acid Supplementation on the Inflammatory Response to eccentric strength exercise. Journal of Sports Science \& Medicine, 10(3), 432-438.

Kotwal, S., Jun, M., Sullivan, D., Perkovic, V., \& Neal, B. (2012). Omega 3 Fatty acids and cardiovascular outcomes: systematic review and metaanalysis. Circulation. Cardiovascular Quality and Outcomes, 5(6), 808-818. https://doi.org/10.1161/ CIRCOUTCOMES.112.966168

Lembke, P., Capodice, J., Hebert, K., \& Swenson, T. (2014). Influence of omega-3 (n3) index on performance and wellbeing in young adults after heavy eccentric exercise. Journal of Sports Science \& Medicine, 13(1), 151-156.

Lewis, E. J. H., Radonic, P. W., Wolever, T. M. S., \& Wells, G. D. (2015). 21 days of mammalian omega-3 fatty acid supplementation improves aspects of neuromuscular function and performance in male athletes compared to olive oil placebo. Journal of the International Society of Sports Nutrition, 12, 28. https:// doi.org/10.1186/s12970-015-0089-4

Macaluso, F., Barone, R., Catanese, P., Carini, F., Rizzuto, L., Farina, F., \& Felice, V. D. (2013). Do fat supplements increase physical performance? Nutrients, 5(2), 509-524. https://doi.org/10.3390/nu5020509

Marik, P. E., \& Varon, J. (2009). Omega-3 dietary supplements and the risk of cardiovascular events: A systematic review. Clinical Cardiology, 32(7), 365-372. https://doi.org/10.1002/clc.20604

Mickleborough, T. D., Sinex, J. A., Platt, D., Chapman, R. F., \& Hirt, M. (2015). The effects PCSO$524 \AA$, a patented marine oil lipid and omega-3 PUFA blend derived from the New Zealand green lipped mussel (Perna canaliculus), on indirect markers of muscle damage and inflammation after muscle damaging exercise in untrained men: A randomized, placebo controlled trial. Journal of the International Society of Sports Nutrition, 12, 10. https://doi.org/10.1186/s12970015-0073-z

Miller, M., Stone, N. J., Ballantyne, C., Bittner, V., Criqui, M. H., Ginsberg, H. N., ... Pennathur, S. (2011). Triglycerides and cardiovascular disease. A scientific statement from the American Heart Association. Circulation, 123(20), 2292-2333. https:// doi.org/10.1161/CIR.0b013e3182160726

Miller, P. E., Van Elswyk, M., \& Alexander, D. D. (2014). Long-chain omega-3 fatty acids eicosapentaenoic acid and docosahexaenoic acid and blood pressure: A metaanalysis of randomized controlled trials. American Journal of Hypertension, 27(7), 885-896. https://doi. org/10.1093/ajh/hpu024 
Morris, M. C., Sacks, F., \& Rosner, B. (1993). Does fish oil lower blood pressure? A meta-analysis of controlled trials. Circulation, 88(2), 523-533.

Mozaffarian, D., Prineas, R. J., Stein, P. K., \& Siscovick, D. S. (2006). Dietary fish and n-3 fatty acid intake and cardiac electrocardiographic parameters in humans. Journal of the American College of Cardiology, 48(3), 478-484. https://doi.org/10.1016/j. jacc.2006.03.048

Oelrich, B., Dewell, A., \& Gardner, C. D. (2013). Effect of fish oil supplementation on serum triglycerides, LDL cholesterol and LDL subfractions in hypertriglyceridemic adults. Nutrition, Metabolism, and Cardiovascular Diseases: NMCD, 23(4), 350-357. https://doi.org/10.1016/j.numecd.2011.06.003

Papanikolaou, Y., Brooks, J., Reider, C., \& Fulgoni, V. L. (2014). U.S. adults are not meeting recommended levels for fish and omega-3 fatty acid intake: Results of an analysis using observational data from NHANES 2003-2008. Nutrition Journal, 13, 31. https://doi. org/10.1186/1475-2891-13-31

Parízková, J., \& Bůzková, P. (1971). Relationship between skinfold thickness measured by Harpenden caliper and densitometric analysis of total body fat in men. Human Biology, 43(1), 16-21.

Raastad, T., Høstmark, A. T., \& Strømme, S. B. (1997). Omega-3 fatty acid supplementation does not improve maximal aerobic power, anaerobic threshold and running performance in well-trained soccer players. Scandinavian Journal of Medicine \& Science in Sports, 7(1), 25-31.
Serhan, C. N., Chiang, N., \& Van Dyke, T. E. (2008). Resolving inflammation: Dual anti-inflammatory and pro-resolution lipid mediators. Nature Reviews. Immunology, 8(5), 349-361. https://doi.org/10.1038/ nri2294

Shearer, G. C., Savinova, O. V., \& Harris, W. S. (2012). Fish oil - how does it reduce plasma triglycerides? Biochimica Et Biophysica Acta, 1821(5), 843-851. https://doi.org/10.1016/j.bbalip.2011.10.011

Shei, R.-J., Lindley, M. R., \& Mickleborough, T. D. (2014). Omega-3 polyunsaturated fatty acids in the optimization of physical performance. Military Medicine, 179(Suppl. 11), 144-156. https://doi. org/10.7205/MILMED-D-14-00160

Stewart, A., \& Marfell-Jones, M. (2011). International standards for anthropometric assessment. Lower Hutt, New Zealand: International Society for the Advancement of Kinanthropometry.

Volpe, S. L. (2012). Fish Oil Supplementation and Athletic Performance. ACSM'S Health \& Fitness Journal, 16(5), 31-32. https://doi.org/10.1249/ FIT.0b013e318264cc25

Walker, C. G., Jebb, S. A., \& Calder, P. C. (2013). Stearidonic acid as a supplemental source of $\omega-3$ polyunsaturated fatty acids to enhance status for improved human health. Nutrition (Burbank, Los Angeles County, Calif.), 29(2), 363-369. https://doi. org/10.1016/j.nut.2012.06.003

Weiner, J. S., \& Lourie, J. A. (1981). Practical human biology. London, UK: Academic Press INC Ltd.
Corresponding author Attila Szabo Institute of Health Promotion and Sport Sciences Eötvös Loránd University Bogdánfy Ödön u. 10, H-1117 Budapest Hungary Tel. +36-70-243-7123

E-mailszabo.attila@ppk.elte.hu 